\title{
Use of Temperature as a Health Monitoring Tool for Solder Interconnect Degradation in Electronics
}

\author{
Preeti Chauhan, Michael Osterman, Michael Pecht \\ CALCE Electronic Products and Systems Center \\ University of Maryland \\ College Park, MD 20742 \\ pecht@calce.umd.edu
}

\author{
Qiang Yu \\ Yokohama National University \\ Yokohama, Japan \\ qiang@ynu.ac.jp
}

\begin{abstract}
Solder interconnects are often the most critical components in electronic assemblies during their operational life. Health assessment of solder interconnects assists in monitoring the degradation of electronic components and predicting their failure. This paper demonstrates the use of temperature as a health assessment tool for implementing prognostics and health management in electronic components. The degradation in varistor solder interconnects due to thermal fatigue damage is assessed using temperature rise. A constant current of 5 amps is passed through the components and the temperature across the solder interconnects is monitored. The temperature rise in the components is found to be directly proportional to the damage undergone by the components due to thermal fatigue. The temperature can thus be used as a means to assess the damage, enabling the health monitoring of the components.
\end{abstract}

Keywords- varistors; solder interconnects; prognostics and health management; reliability; thermal fatigue

\section{INTRODUCTION}

Prognostics for electronic products and systems has received increased attention due to its potential to provide early warning of impending failures, forecast maintenance, and reduce life cycle costs [2]. There are several approaches for the implementation of prognostics, including the monitoring of precursors to failure, use of canary devices [3][4][5][6], and monitoring of environmental and usage conditions experienced by a product in its application environment. Prognostics uses data obtained through these methods along with damage models to assess the extent of deviation or degradation of a product from its expected normal operating condition due to environmental exposure during its service life and/or predict its remaining useful life.

Temperature cycling is a prominent reliability test for solders in electronic equipment [7]. Temperature cycle-induced solder interconnect fatigue is a process of crack initiation and propagation driven by cyclic mechanical strain in the solder arising from a coefficient of temperature expansion (CTE) mismatch between the component and the printed circuit board, as well as the solder and the solder interface.
In this paper, the efficacy of the use of temperature rise as a health assessment tool for solder interconnects degradation under thermal fatigue is demonstrated. The test specimens were insertion-mount varistors soldered with $\mathrm{Sn} 99.3 \mathrm{Cu}+\mathrm{Ni}(\mathrm{Ge})$ (SN100C) and conventional Sn37Pb solder. From the literature, $\mathrm{SnCu}$ alloys are one of the lead-free solders currently utilized by the electronics industry. They have the advantages of lower cost [8] and lower copper dissolution than SAC solders [9]. $\mathrm{SN} 100 \mathrm{C}$ is the dominant $\mathrm{SnCu}$ alloy currently in use. SN100C is based on the $\mathrm{Sn} 0.7 \mathrm{Cu}$ solder and adds $\mathrm{Ni}-\mathrm{Ge}$ to the composition. Compared with $\mathrm{Sn} 0.7 \mathrm{Cu}, \mathrm{SN} 100 \mathrm{C}$ has a smoother solder joint appearance, finer grains, and a better high temperature performance [10][11].

The test specimens were subjected to temperature cycle tests with a temperature range of $-40^{\circ} \mathrm{C}$ to $125^{\circ} \mathrm{C}$, and resistance change was monitored. The damage assessment approach was demonstrated on the specimens exposed to 1500 and 4500 cycles. Constant direct current was passed through the test specimens and temperature rise was monitored, which was related to the thermal fatigue damage in the specimens. Hence, a non-destructive technique for damage assessment of solder interconnects is demonstrated.

\section{TEMPERATURE CYLCING TEST}

Figure 1 shows the test board consisting of through-hole varistors and surface mount resistor components. In this study, the varistors components are examined. The test vehicle contained 72 varistors assembled with SN100C and $\mathrm{SnPb}$ solders on the printed circuit board (PCB). The test boards were constructed of flame retardant (FR4) material with a total thickness of $1.6 \mathrm{~mm}$. The insertion holes were plated with $0.025 \mathrm{~mm}$ copper. 


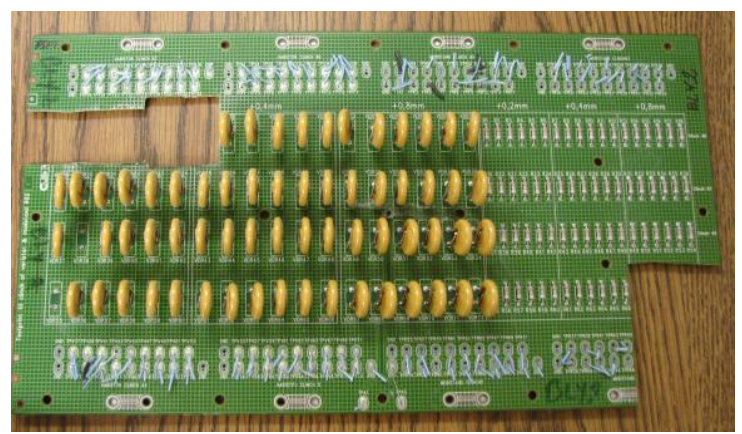

Figure 1: Test Vehicle

To form a resistance network, the varistor components were shorted with a metal jumper wire that was connected to the two insertion mount lead wires. Test boards were subjected to a $40^{\circ} \mathrm{C}$ to $125^{\circ} \mathrm{C}$ temperature cycle test.

Figure 2 shows the test specimen and the thermal cycling chamber for the test.

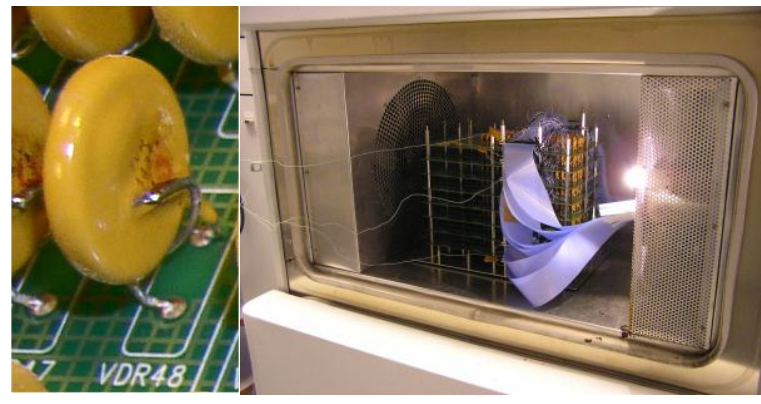

Figure 2: Thermal Cycling Test

Resistance monitoring was carried out to examine the electrical continuity of the specimens. Failure criterion was based on the resistance increase as per IPCSM-785 [12].

The test boards were removed after being subjected to 750 , 1500,3000 , and 4500 temperature cycles. No electrical failure was recorded in the insertion mount solder interconnects upon exposure to 4500 cycles. Similar findings were observed in the modeling of the test assembly using calceSARA, where no failures were observed in the test specimens for up to 4500 cycles.

\section{USE OF TEMPERATURE AS AN INDICATOR OF SOLDER INTERCONNECT DAMAGE}

After the thermal cycling tests on the specimens, the degradation due to thermal fatigue was assessed using the temperature rise due to the passage of electrical current. The approach for the health assessment of solder interconnects in varistors is discussed below.

\section{A. Approach}

It is known that the solder interconnect degradation under temperature cycling corresponds to an increase in resistance. Thus, upon passage of electrical current, the components experiencing more damage would show a higher temperature rise, resulting from higher Joule heating. Based on this, a nondestructive estimation of damage can be made by monitoring temperature rise due to Joule heating. In the present test, a constant direct current (DC) of 5 amps was applied to the specimens and temperature rise across the solder joints was recorded. A comparison of the temperature rise in specimens subjected to various durations of thermal cycling was made. Table 1 shows the test matrix for the study. In this paper, the comparison between test specimens exposed to 1500 and 4500 cycles is presented.

TABLE 1: TEST MATRIX

\begin{tabular}{|c|c|c|c|c|c|}
\hline $\begin{array}{c}\text { Solder } \\
\text { Type }\end{array}$ & $\begin{array}{c}\text { Sample } \\
\text { Size }\end{array}$ & \multicolumn{4}{|c|}{ Thermal Cycles } \\
\hline SN100C & 3 & 750 & 1500 & 3000 & 4500 \\
\hline $\mathrm{SnPb}$ & 3 & 750 & 1500 & 3000 & 4500 \\
\hline
\end{tabular}

\section{B. Test Setup}

Figure 3 shows the test setup for the temperature rise measurement in the varistors due to the passage of electrical current. The power supply applies the current through the probes and the temperature is recorded on the back side of the test board at three locations - the printed circuit board (PCB) and the two solder interconnect locations - using K-type thermocouples every 10 seconds.

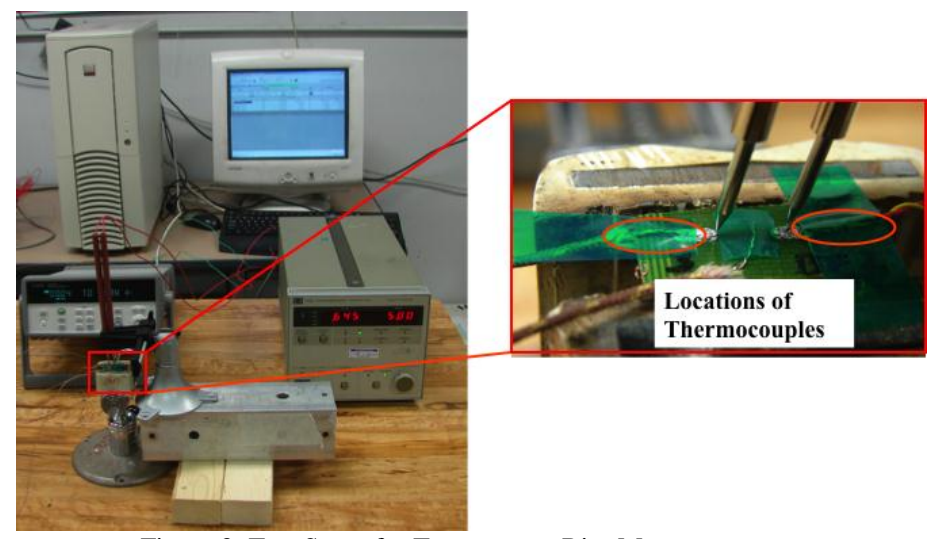

Figure 3: Test Setup for Temperature Rise Measurement

Figure 4 shows the location of the thermocouples and the current supply points. A constant direct current was passed for four hours and the temperature was recorded.

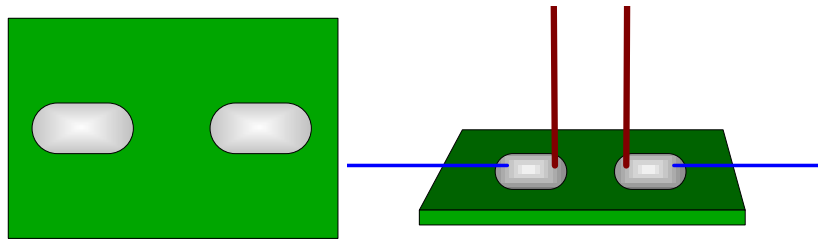

Figure 4: Location of Current Supply Points and Thermocouples

\section{Results}

Solder interconnect temperature was recorded as the current was passed through the specimens. The plot of solder interconnect temperature vs. time is shown in Figure 6-Figure 7 for $\mathrm{SN} 100 \mathrm{C}$ and $\mathrm{SnPb}$ solder interconnects, respectively. 


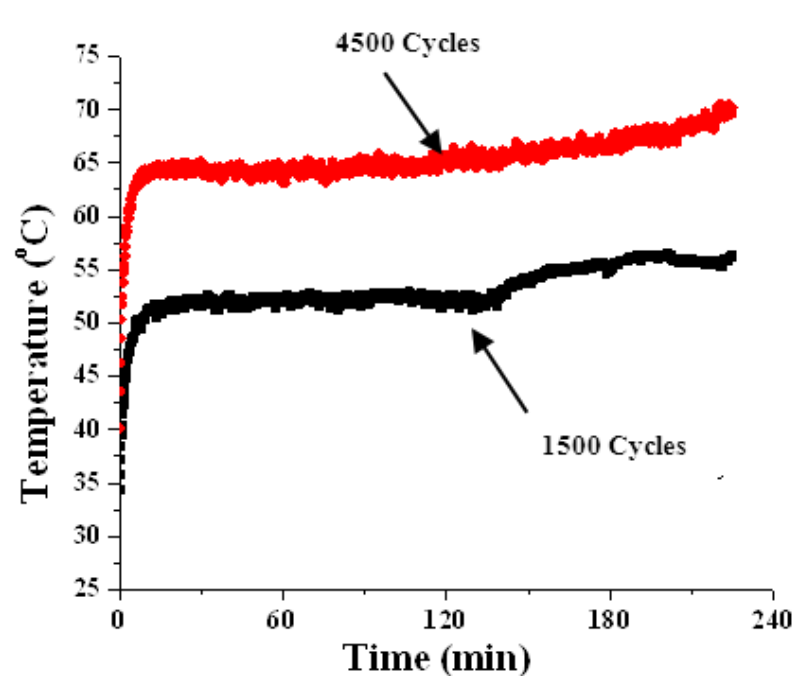

Figure 5: Temperature vs. Time- SN100C Solder

It can be seen that the SN100C solder interconnects exposed to 4500 cycles showed a higher temperature rise (up to $\sim 15^{\circ} \mathrm{C}$ ) than the ones exposed to 1500 cycles.

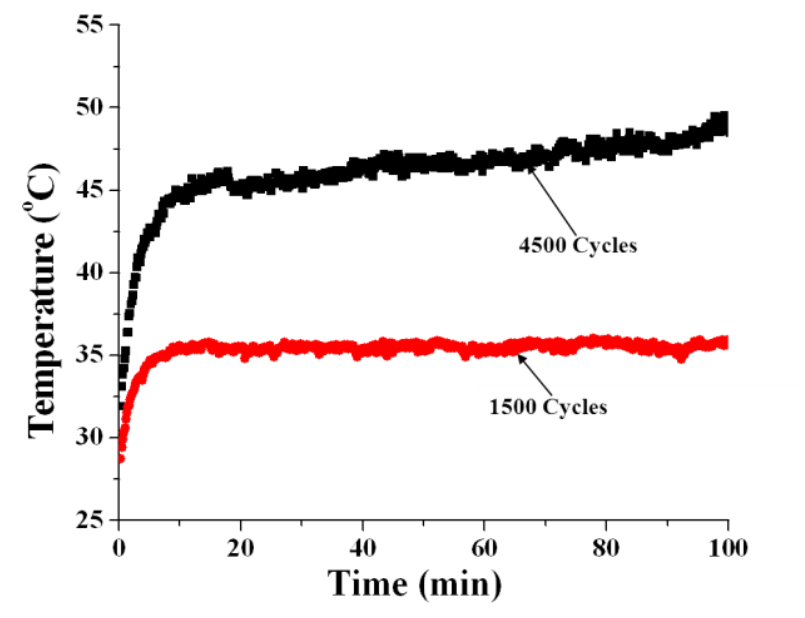

Figure 6: Temperature vs. Time- $\mathrm{SnPb}$ Solder

Similarly, the temperature rise across $\mathrm{SnPb}$ interconnects exposed to 4500 cycles showed a higher temperature rise (up to $\sim 15^{\circ} \mathrm{C}$ ) than the ones exposed to 1500 cycles.

Next, optical inspection was conducted to examine the damage in the solder interconnects due to thermal cycling and related to the temperature rise due to Joule heating.

\section{Optical Inspection}

Optical inspection of the test specimens was carried out to assess the damage in the cycled specimens as a function of number of cycles. Figure 7 (a) and (b) shows the comparison of the optical images of SN100C test specimens cycled for 1500 and 4500 cycles, respectively. The images show the solder location at the back side of the specimens.
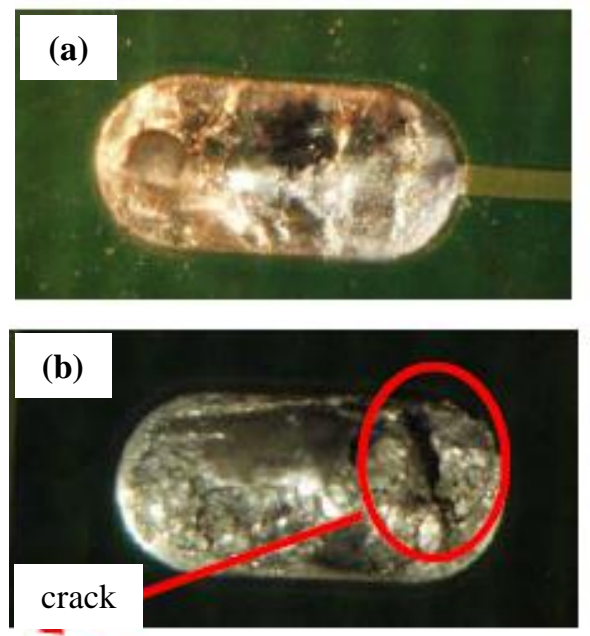

Figure 7: Optical Inspection of SN100C Soldered Specimens after (a) 1500 Cycles (b) 4500 Cycles

Figure 8: Optical Inspection of $\mathrm{SnPb}$ Soldered Specimens after (a) 1500 Cycles (b) 4500 Cycles

The damage can be seen in the form of grainier solder interconnects in the specimens with more damage. The change in surface appearance is in part due to oxidation from the elevated temperature exposure.

Hence, the optical inspection confirms that the specimens with a higher temperature rise have incurred higher damage.

Figure 8 (a) and (b) shows the comparison of $\mathrm{SnPb}$ soldered specimens having undergone 1500 and 4500 cycles, respectively. It can be seen that the specimens exposed to 4500 cycles show more damage than the ones cycled for 1500 cycles.
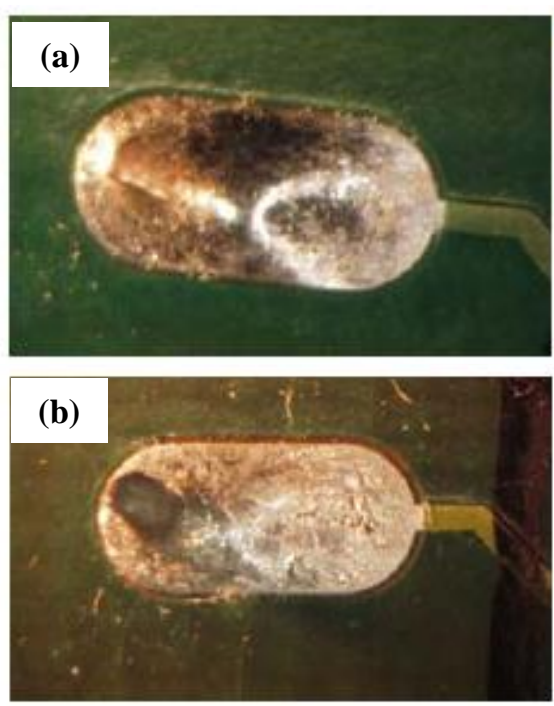

Figure 8: Optical Inspection of $\mathrm{SnPb}$ Soldered Specimens after (a) 1500 Cycles (b) 4500 Cycles 
The damage can be seen in the form of grainier solder interconnects in the specimens with more damage. The change in surface appearance is in part due to oxidation from the elevated temperature exposure.

Hence, the optical inspection confirms that the specimens with a higher temperature rise have incurred higher damage.

\section{SUMMARY AND CONCLUSIONS}

An approach for the health assessment of insertion mount varistors using temperature has been demonstrated. The thermal fatigue damage in the solder interconnects was assessed using the temperature rise method. It was found that the test specimens that experienced more damage as a result of a higher number of cycles showed a higher temperature rise under the passage of current. The temperature rise in the specimens corresponds to the resistance of the test specimens. The specimens incurring more damage have higher resistance. Hence, the Joule heat generated in these specimens is higher than in the specimens exposed to a lesser number of thermal fatigue cycles. The results of optical inspection validated these findings.

This approach can be extended to be used as a failure precursor of solder interconnects, where the remaining useful life of the solders can be predicted based on the temperature rise across the solder interconnects.

\section{ACKNOWLEDGMENT}

The authors would like to thank the more than 100 companies and organizations that support research activities at the Center for Advanced Life Cycle Engineering at the University of Maryland.

\section{REFERENCES}

[1] L. Nie, M. Osterman, and M. Pecht, "Solder Degradation of Assembled Insertion-Mount Varistors and Resistors".
[2] M. Pecht, Prognostics and Health Management of Electronics, WileyInterscience, 2008.

[3] D. Goodman, Vermeire, B.; Ralston-Good, J.; and Graves, R.; "A Board-Level Prognostic Monitor for MOSFET TDDB," IEEE Aerospace Conference, 2006.

[4] C.Y. Yin, H. Lu, M. Musallam, C. Bailey, C.M. Johnson, "A Physics-offailure based Prognostic Method for Power Modules", 10th Electronics Packaging Technology Conference, pp. 1190-1195, 2008.

[5] N. Anderson, R. Wilcoxon, "Framework for Prognostics of Electronics Systems", International Military \& Aerospace / Avionics Cots Conference, Exhibition \& Seminar, 2004.

[6] J.H. Lau, "The Roles of DNP (Distance to Neutral point) on Solder Joint Reliability of Area Array Assemblies", Express Packaging Systems, Inc., Palo Alto, California, USA, Soldering \& Surface Mount Technology, Vol. 9, No. 2, pp. 58-60, 1997.

[7] R. Coyle, M. Reid, C. Ryan, R. Popowich, P. Read, D. Fleming, M. Collins, J. Punch, and I. Chatterji, "The influence of the Pb-free solder alloy composition and processing parameters on thermal fatigue performance of a ceramic chip resistor", Proceedings of 59th Electronic Components and Technology Conference, pp. 423-430, 2009.

[8] C. Thanachayanont and N. Ramungul, "Low-Cost Lead-Free Solder for EE Industries", IEEE International Conference on Industrial Technology, pp. 1213-1218, 2002,

[9] C. Hamilton, P. Snugovsky and M. Kelly, "A Study of Copper Dissolution During Lead Free PTH Rework Using A Thermally Massive Test Vehicle", Proceedings of SMTA International 2006, SMTA Edina, MN, pp. 177-182, 2006.

[10] M. Laentzsch, "Theory and Practical Experience of Micro-Alloyed $\mathrm{SnCu} 0.7 \mathrm{NiGe}$ (SN100C)", Proceedings of 1st Electronics Systemintegration Technology Conference, Dresden, Germany, Vol.1, pp. 383-386, 2006,

[11] E. Havia, H. Montonen, E. Bernhardt and M. Alatalo, "Comparing SAC and SnCuNi Solders in Lead-Free Wave Soldering Process", NEXT, 2005, last accessed on 27 March 2012, http://www.3ktehdas.com/uutiset/Next_05.pdf

[12] "Guidelines for accelerated reliability testing of surface mount solder attachments", IPC-SM-785, 1992. 